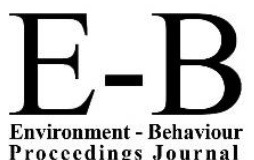

Procecdings Journal
AIVCE-BS-2, 2020ShahAlam

https://www.amerabra.org; https://fspu.uitm.edu.my/cebs; https://www.emasemasresources.com/ AMEABRA International Virtual Conference on Environment-Bahaviour Studies, ${ }^{\text {nd }}$ Series cE-Bs, FSPU, Universiti Teknologi MARA, Shah Alam, 02-03 Dec 2020

\section{e-IPH}

e-International Publishing House Ltd. United Kingdom

\title{
Using Structural Equation Modeling to Evaluate Tourists' Revisit Intention toward Ecotourism Sites
}

\author{
Heng Zhang, Nam Nguyen-Dinh, Zhi-Wei Pan \\ Department of Architecture, \\ National Cheng Kung University, Tainan City, Taiwan \\ changlin@mail.ncku.edu.tw,n78077015@gs.ncku.edu.tw, B23631@yahoo.com.tw \\ Tel: +886-917-798-255
}

\begin{abstract}
This study aims to clarify the relationship between three behaviours toward ecotourism sites include "ecotourism attitude," "ecotourism experience," and "revisit intention." The structural equation modeling was used to evaluate how the attitude of ecotourism and the visit experience impact the tourists' revisit intention. The analysis indicated that three constructs logically are suitable for the research direction after the test of the validity of measurement models. The structural model revealed that both "ecotourism attitude" and "ecotourism experience" positively influence "revisit intention." Especially, "experience" also plays as a mediator, which causes the indirect effect of ecotourism attitude on revisit intention.
\end{abstract}

Keywords: Ecotourism attitude; Ecotourism experience; Revisit intention.

eISSN: 2398-42870 2020. The Authors. Published for AMER ABRA CE-Bs by e-International Publishing House, Ltd., UK. This is an open access article under the CC BYNC-ND license (http://creativecommons.org/licenses/by-nc-nd/4.0). Peer-review under responsibility of AMER (Association of Malaysian Environment-Behaviour Researchers), ABRA (Association of Behavioural Researchers on Asians) and cE-Bs (Centre for Environment-Behaviour Studies), Faculty of Architecture, Planning \& Surveying, Universiti Teknologi MARA, Malaysia.

DOI: https://doi.org/10.21834/ebpj.v5i15.2459.

\subsection{Introduction}

Ecotourism is considered a green industry, positively contributing to economic, cultural, and social in local. This field bases on the natural experience and conservation of the cultural history and the landscape environment of the ecotourism sites. Through ecotourism, travellers have further chances to experience, discover, and learn the exciting characteristics of various cultures. Besides, the psychologies toward ecotourism could be impacted, including ecotourism attitude, visit experience, and even the revisit intention of the travellers. Thus, the ecotourism behaviours could become an important theme for the behavioural researchers and tourism managers. To develop ecotourism communities, and enhance the conservation capacity and become a major budget for the local, the Tainan City government always has many favourable support policies for the projects of research and development of the potential ecotourism sites. Based on the theories of behavioural research toward ecotourism and the real conditions of Tainan City, the study conducted an investigation in two tourism places, the Sicao community, locates in Annan District, and the Wangcheng west community locates in Anping District. Through the data from the survey of tourism behaviour, the research analysis shows up the evaluations of the relationship among the tourists' ecotourism psychology, including ecotourism attitude, visit experience, and revisit intention.

eISSN: 2398-4287C 2020. The Authors. Published for AMER ABRA cE-Bs by e-International Publishing House, Ltd., UK. This is an open access article under the CC BYNC-ND license (http://creativecommons.org/licenses/by-nc-nd/4.0/). Peer-review under responsibility of AMER (Association of Malaysian Environment-Behaviour Researchers), ABRA (Association of Behavioural Researchers on Asians) and cE-Bs (Centre for Environment-Behaviour Studies), Faculty of Architecture, Planning \& Surveying, Universiti Teknologi MARA, Malaysia.

DOI: https://doi.org/10.21834/ebpj.v5i15.2459. 


\subsection{Literature Review}

\subsection{The attitude and the visit experience toward ecotourism sites}

From 1965 the definition of ecotourism was called by Hetzer; the scholar suggested people more take care of the culture, education, tourism, and advocate for ecotourism (Ashok, Tewari, Behera, \& Majumdar, 2017). Today, ecotourism plays a kind of tourism that relates to the field of environment, and culture, which adapts to environmental conservation, ecological sustainability, and economy (Reimer \& Walter, 2013). According to recent studies, the perception, emotion, and place attachment of people were impacted by the visual factors in communities (Zhang \& Lin, 2011; Zhang, Nam, \& Hu, 2020). Thus, through visiting ecotourism sites, the people have more chances to interact with the landscape environment, which can affect the feeling and the attitude toward the ecotourism environment. A study by Lee Woo Hee pointed out that the attitude toward ecotourism is considered as an essential role in the process of environmental education (T. H. Lee \& Jan, 2018; W. H. Lee \& Moscardo, 2005). Additionally, the ecotourism attitude could seem as the core cause, which affinity the expect of a visit experience to satisfy the need of discovery the cultural value, and historical value in the other local (CastellanosVerdugo, Vega-Vázquez, Oviedo-García, \& Orgaz-Agüera, 2016; Oviedo - García, Castellanos - Verdugo, Vega - Vázquez, \& Orgaz - Agüera, 2017).

\subsection{The attitude toward ecotourism and the revisit intention}

The attitude precedes the intention; therefore, the attitude can lead to the change of the extent to which people plan to exert in the future (Ajzen, 2001). Infield of ecotourism, ecotourism intention refers to the visitors' plan to participant in ecotourism in the future. A good ecology environmental attitude positively influences intentions for ecotourism forms as well as for choosing ecotourism sites (Han, Hsu, \& Sheu, 2010). On the other hand, to improve the environment and conserve nature, environmental education needs to be integrated into the travel programs (Aswita, 2018). Thus, successful ecotourism must be based on the environmental knowledge through the ecotravels and the extent of the expectation to revisit to the ecotourism places of tourists (Hultman, Kazeminia, \& Ghasemi, 2015).

\subsection{Ecotourism attitude, ecotourism experience, and revisit intention}

Tourism quickly helps the visitors perceive the characteristics of local landscapes. Through the experience of the worth landscape environment, people can relieve the stress of life. Particularly, the visitors have more opportunities to interact with the environment and culture-social condition of the tourism sites to satisfy their needs to relax and collect the worth knowledge about nature conservation. Thus, the mediating effect of visit experience is considered a bridge between the physical environment and tourists' inside-feeling and promotes tourists' revisit intention in the future (Huang \& Liu, 2017; Liu \& Huang, 2017).

\subsection{Proposed structural model}

Through tourism theories, the study proposed a structural equation modeling to make a bright on the relationship between the attitude, experience, and revisit intention toward ecotourism. The research proposed four effect hypothesizes of the tourism behaviours as below (Figure 1):

$\mathrm{H1}$ : Ecotourism attitude of tourists positively affects the ecotourism experience.

$\mathrm{H}$ 2: Ecotourism experience positively affects revisit intention of tourists.

$\mathrm{H} 3$ : Ecotourism attitude positively affects revisit intention of tourists.

$\mathrm{H}$ 4: Ecotourism experience has a mediating effect on the relationship of ecotourism attitude and revisit intention. Besides, there is an indirect effect of ecotourism attitude on revisit intention.

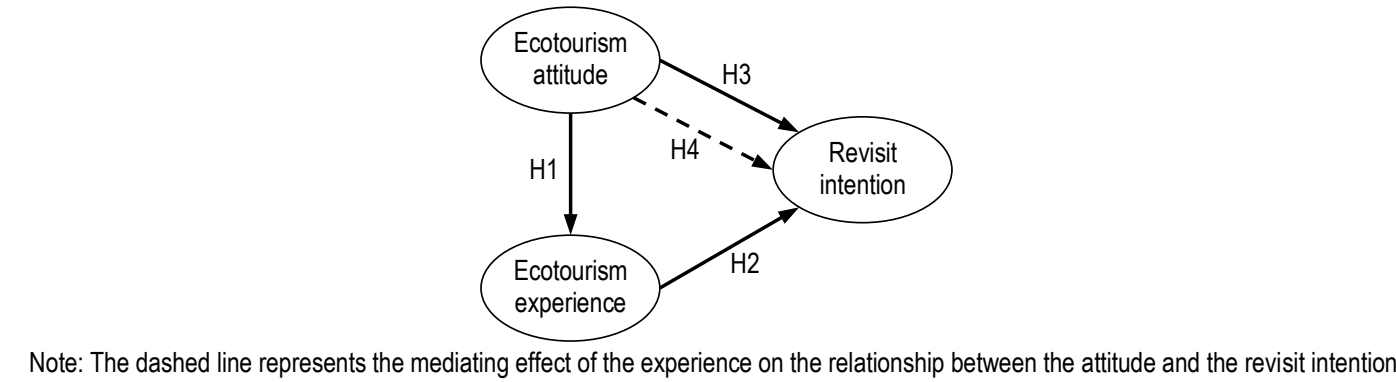

Note: The dashed line represents the mediating effect of the experience on the relationship between the attitude and the revisit intention.

Figure. 1. Proposed structural model for research.

(Source: Author)

\subsection{Methodology}

\subsection{Site Studies}

The sites studied are the Sicao community and Wangcheng west community (Figure 2). Both communities are located in Southwest Tainan City, Taiwan, and they are considered potential places for tourism for the City. The Sicao community belongs to Annan District, where be known as a small fishing village with many tourist places such as Sicao lake, Sicao fort, Dazhong temple, and Sicao park. The 
residents mainly rely on offshore aquaculture for their livelihoods, such as oysters, prawns, milkfish, and other aquatic products cultivated along the coast of Luermen Xikou. The tourists love to go here to satisfy their natural experience.

The Wangcheng west community belongs to Anping District and is located in Southwest of Tainan city. This area is on the west of Wangcheng in the ancient castle of Anping, including Anping Castle, Dongxing Ocean Walk, Xilong Temple, Anping Tianhou Palace, Lujia Ancient House, Wangjia Ancient Temple, Small Fort, and Qianlong ancient embankment. Most of the tourists usually visit the Wangcheng west community for the cultural experience.

To make the quality of tourism in the two communities better and more attractive to the tourists, the Tainan government always gives the best policies for conserving the ecology environment and characteristic culture and supports the economy locally. Therefore, the study is interested in two ecotourism communities.
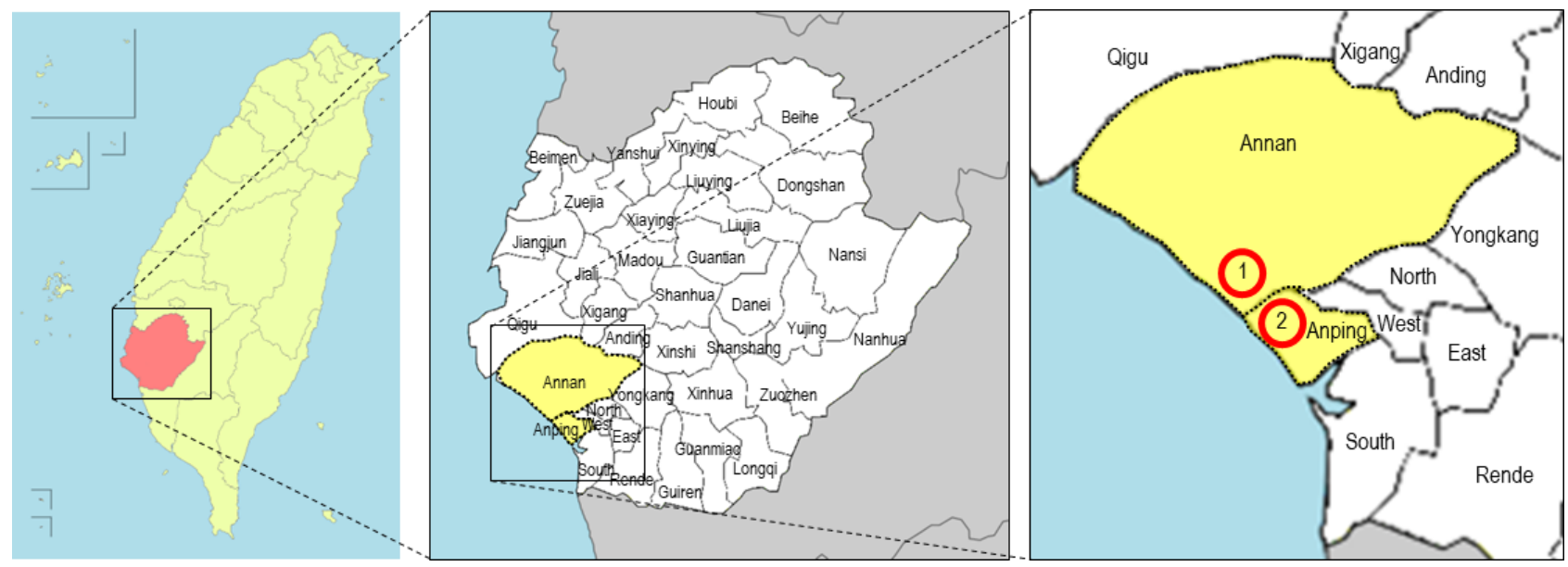

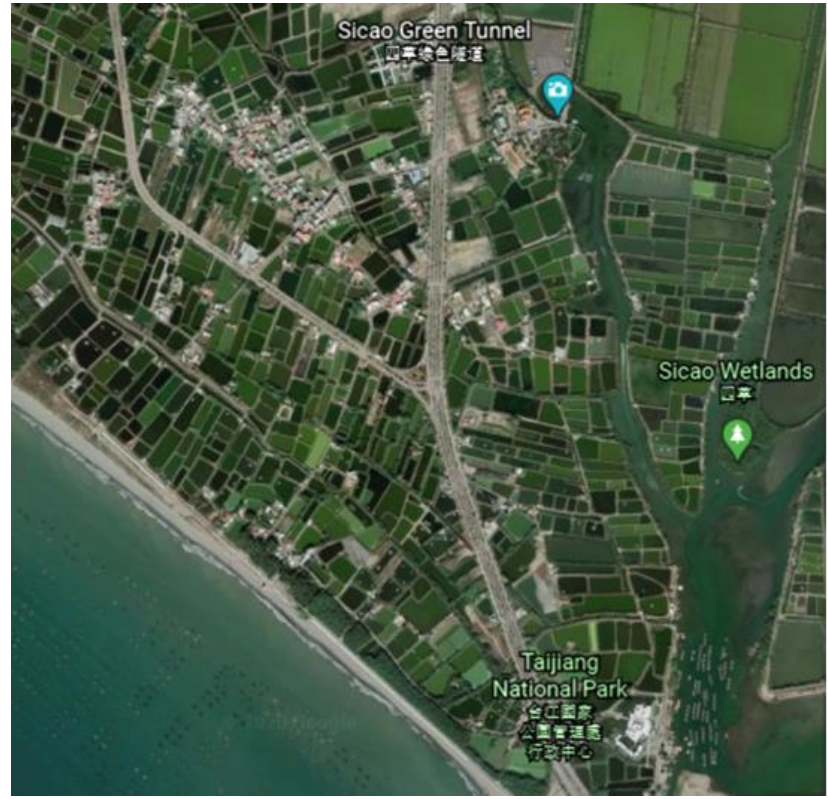

(1) Sicao community

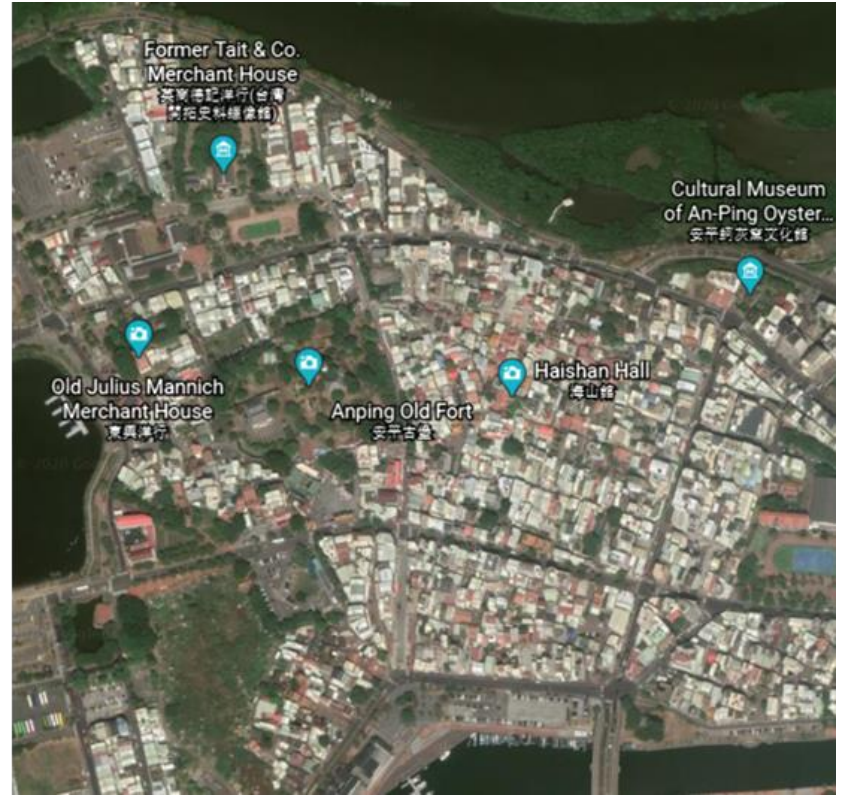

(2) Wangcheng west community

Figure. 2. Map of the study site. (Source: Author)

\subsection{Measurement of variables}

The questionnaire was designed based on the literature review and was pre-tested to ensure the validity of internal items to support the study. There were three sections in the questionnaire, which represent three study constructs. The five-point Likert scale was applied for all constructs; it ranged from 1 (very disagree) to 5 (very agree).

\subsubsection{Attitude toward ecotourism sites}

The study showed up four questions in order to evaluate the ecotourism attitude, i.e., "ecotourism should focus on appreciating and experiencing natural and cultural resources" (EA1), "conservation and preservation of tourism resources are more important than socialeconomic functions" (EA2), "ecotourism development should focus on environmental education" (EA3), and "Ecotourism should be dominated by small groups of tourists" (EA4). 


\subsubsection{Experience in ecotourism sites}

There are five questions designed in order to collect the thinking and feeling of tourists. These elements aim to evaluate the worth experiments after a journey in ecotourism zones, i.e., "I think the scenic relics of this tour are very attractive to me" (EE1), "The local scenery and cultural relics moved me" (EE2), "This trip made me think and spark curiosity" (EE3), "The local environment makes me want to take pictures and share my experience" (EE4), and "This tour strengthened my sense of protection for the local environment" (EE5).

\subsubsection{Revisit intention in ecotourism sites}

The study asked the respondents to answer four questions to investigate tourists' expects in order to evaluate the revisit intention toward ecotourism sites, such as whether they want to come back to areas again and what they will do in the next tours in ecotourism zones. The internal items of this construct comprise "I will pay attention to my behaviours during travel to avoid destroying the ecology" (RI1), "I would like to revisit this tourism site again" (RI2), "I would like to travel by bicycle or foot" (RI3), and "If necessary, I am willing to contribute to the tourism destination to promote conservation" (RI4).

\subsection{Data collection}

The study conducted a face to face survey in two ecotourism sites, Sicao community and Wangcheng west community. The former site places in Annan District, and the last site places in Anping District, Tainan City. After the survey, the study collected 322 valid questionnaires relevant to the ecotourism behaviours. The respondents were from under 20 up to above 61 years old, who are the tourists in these tourism sites.

\subsection{Data analysis}

\subsubsection{Evaluating the fit of the proposed structural model}

The study tested the validity of the measurement models to determine whether the observed variables logically are suitable with the research direction and could represent the three constructs, including "ecotourism attitude," "ecotourism experience," and "revisit intention" (Hair, 2016). Next, the method of structural equation modeling (SEM) analyzed the proposed structural model.

\subsubsection{Evaluating the mediating effect}

The paper pointed out that the mediating effect certainly exists in the proposed model based on the literature. Thus, the statistical method was recommended to test the mediating effect and evaluate how much the effect size in this relationship (Hair, 2016).

\subsection{Results and Discussion}

\subsection{Profile of the samples}

Table 1 indicated the characteristic of the respondents. The proportion of males (52.8\%) was higher than females (47.2\%). Most of the visitors were between 20 and 40 (87.4\%), especially the visitors from 21 to 30 keeps the highest level (40.8\%). Besides, the respondents have the education level of university/ college are largest $(60.2 \%)$, and the proportion of students is $38.1 \%$. Based on the sample profile, the study also revealed that the tourists often use public transportation (17.3\%), train (34.6\%), and car $(40.9 \%)$ to reach the tourism communities, while bicycle was used fewer (7.2\%). They also had the trend of tourism group with friends $(66.5 \%)$ or with family $(30.5 \%)$, whereas the number of visitors loving travel alone just was smallest $(2.8 \%)$. Based on the information about the survey, the characteristics of the samples were suitable for this research.

Table 1: The Characteristics of the samples.

\begin{tabular}{|c|c|c|c|c|c|}
\hline Characteristics & Respondent & Percentage & Characteristics & Respondent & Percentage \\
\hline Gender & & & Industrial/ & 53 & 168 \\
\hline Male & 167 & 52.8 & Manufacturing & & \\
\hline Female & 149 & 47.2 & Business/Service & 69 & 21.9 \\
\hline Age & & & Military education & 27 & 8.6 \\
\hline Under 20 & 62 & 19.4 & Housekeeper & 12 & 3.8 \\
\hline $21-30$ years old & 130 & 40.8 & Retire & 1 & 0.3 \\
\hline $\begin{array}{l}31-40 \text { years old } \\
41-50 \text { years old }\end{array}$ & $\begin{array}{l}88 \\
32\end{array}$ & $\begin{array}{l}27.6 \\
10.0\end{array}$ & $\begin{array}{c}\text { Other } \\
\text { Transportation }\end{array}$ & 30 & 9.5 \\
\hline $51-60$ years old & 6 & 1.9 & Bicycle & 23.0 & 7.2 \\
\hline Above 61 & 1 & 0.3 & Public transport & 55.0 & 17.3 \\
\hline Education & & & Locomotive & 110.0 & 34.6 \\
\hline $\begin{array}{l}\text { Elementary/Middle school } \\
\text { High school/Nocational }\end{array}$ & $\begin{array}{l}8 \\
53\end{array}$ & $\begin{array}{l}2.5 \\
16.9\end{array}$ & $\begin{array}{c}\text { Car } \\
\text { Tourism group }\end{array}$ & 130.0 & 40.9 \\
\hline College/University & 189 & 60.2 & Travel alone & 9.0 & 2.8 \\
\hline $\begin{array}{l}\text { Graduate school } \\
\text { Occupation }\end{array}$ & 64 & 20.4 & $\begin{array}{l}\text { Travel with friends } \\
\text { Travel with family }\end{array}$ & $\begin{array}{l}211.0 \\
97.0\end{array}$ & $\begin{array}{l}66.5 \\
30.5\end{array}$ \\
\hline Student & $\begin{array}{l}120 \\
3\end{array}$ & $\begin{array}{l}38.1 \\
1.0\end{array}$ & $\begin{array}{l}\text { Sicao community } \\
\text { Wangcheng west community }\end{array}$ & $\begin{array}{l}124 \\
198 \\
\end{array}$ & $\begin{array}{l}38.5 \\
61.5\end{array}$ \\
\hline
\end{tabular}




\begin{tabular}{lrr}
$\begin{array}{l}\text { Agriculture, forestry, fishery } \\
\text { and animal husbandry }\end{array}$ & Total & 100 \\
\hline & (Source: & Author)
\end{tabular}

\subsection{Reliability analysis}

To examine the reliability of the three constructs, the study tested a correlated item-total correlation of the individual items to each construct (Bazazo, Nasseef, Al-Zawaideh, Al-Zawaideh, \& Al-Dhomaidat, 2017; Zhang et al., 2020). Refer to the construct of ecotourism attitude (EA), the correlation of the item EA4 "small tour group" $(0.22)$ was lower than the threshold value of 0.30 , and need to be removed. After removing the item EA4, the Cronbach's alpha increased from 0.604 to 0.698 . The two constructs, ecotourism experience $(\mathrm{EE})$ and revisit intention (RI), indicated that all of the items are suitable for the research. Ecotourism experience (EE) had 0.813 of the Cronbach's alpha, and revisit intention (RI) had 0.764 .

\subsection{Validity of the measurement model}

Next, the study evaluated the validity of the measurement model for three constructs (Hair, 2016). The goodness-of-fit (GOF) showed that the $p$-value of the test was significant $(0.000)$, and the proposed model had an acceptable data fit $\left(X^{2}=100.289, \mathrm{df}=51, \mathrm{X}^{2} / \mathrm{df}=\right.$ $1.966, \mathrm{CFI}=0.955, \mathrm{GFI}=0.953, \mathrm{AGFI}=0.928, \mathrm{NFI}=0.914, \mathrm{RMSEA}=0.055, \mathrm{RMR}=0.026, \mathrm{PNFI}=0.706)$. Through the GOF, the proposed model adequately explained the relationship between the research variables. In addition, the value of $X^{2}$ significantly showed the sensitivity to the sample size, and the validity of the measurement model was confirmed. All loadings of indicators in three constructs were estimated from 0.577 to 0.792 (Table 2).

Table 2: Convergent validity of the measurement models.

\begin{tabular}{|c|c|c|c|c|c|}
\hline Construct/Indicator & Factor loading $(\lambda)$ & Reliability coefficient $\left(\lambda^{2}\right)$ & Measurement error $\left(1-\lambda^{2}\right)$ & AVE (b) & $\mathrm{CR}(\mathrm{c})$ \\
\hline Ecotourism attitude & & & & 0.467 & 0.712 \\
\hline EA1 & $0.792(a)$ & 0.627 & 0.373 & & \\
\hline EA2 & $0.608^{* * *}$ & 0.370 & 0.630 & & \\
\hline EA3 & $0.608^{* * *}$ & 0.370 & 0.630 & & \\
\hline Ecotourism experience & & & & 0.456 & 0.814 \\
\hline EE1 & $0.747(a)$ & 0.558 & 0.442 & & \\
\hline EE2 & $0.677^{* * *}$ & 0.458 & 0.542 & & \\
\hline EE3 & $0.701^{* * *}$ & 0.491 & 0.509 & & \\
\hline EE4 & $0.633^{\star \star *}$ & 0.401 & 0.599 & & \\
\hline EE5 & $0.654^{\star \star *}$ & 0.428 & 0.572 & & \\
\hline Revisit intention & & & & 0.452 & 0.765 \\
\hline RI1 & $0.623^{* \star *}$ & 0.388 & 0.612 & & \\
\hline $\mathrm{R} / 2$ & $0.770(a)$ & 0.593 & 0.407 & & \\
\hline RI3 & $0.577^{\star \star \star}$ & 0.333 & 0.667 & & \\
\hline $\mathrm{R} 14$ & $0.703^{* \star *}$ & 0.494 & 0.506 & & \\
\hline
\end{tabular}

Note: ${ }^{*} p<0.05 ;{ }^{* *} p<0.01 ;{ }^{* * *} p<0.001$.

a: Significance was not calculated because the unstandardized loading was set as 1.0 to fix construct variance.

b: Average variance extracted $=\left(\sum \lambda^{2}\right) / n$ (where $n$ is the number of items).

c: Composite reliability $=\left(\sum \lambda\right)^{2} /\left[\left(\sum \lambda\right)^{2}+\left(\sum\right.\right.$ error $\left.)\right]$.

(Source: Author)

The composite reliability (CR) of three constructs was estimated from 0.712 to 0.814 , and higher than the threshold value of 0.7 (Hair, 2016). The average variance extracted (AVE) of ecotourism attitude (0.467), ecotourism experience (0.456), and revisit intention (0.452) were slightly below 0.50 (Hair, 2016). However, an AVE below 0.50 is still acceptable because its composite reliability (CR) is greater than a threshold value of 0.70 , and the correlated item-total correlation over the recommended level of 0.40 (Bufquin, DiPietro, Park, \& Partlow, 2017).

In order to examine the discriminant validity, the study compared the average variance extracted (AVE) and squared correlation ( $\left.\mathrm{X}^{2}\right)$ among three constructs (Table 3). The analysis exhibited that all of the average variance extracted is greater than squared correlations. Thus, the three constructs' discriminant validity was totally significant and revealed that the construct validity of the measurement models was adopted with the research condition.

Table 3: Discriminant validity of the measurement models.

\begin{tabular}{|c|c|c|c|c|c|}
\hline & MSV & $\operatorname{MaxR}(\mathrm{H})$ & Ecotourism experience & Ecotourism attitude & Revisit intention \\
\hline Ecotourism experience & 0.319 & 0.818 & 0.684 & & \\
\hline
\end{tabular}




\begin{tabular}{llllll} 
Ecotourism attitude & 0.147 & 0.741 & $0.239^{* \star *}$ & 0.675 & \\
Revisit intention & 0.319 & 0.781 & $0.565^{* \star *}$ & $0.384^{* \star *}$ & 0.672 \\
\hline
\end{tabular}

Note: ${ }^{*} p<0.05 ;{ }^{* *} p<0.01 ;{ }^{* *} p<0.001$

(Source: Author)

\subsection{Validity of the structural model}

To exam the validity of the structural model, the goodness-of-fit was assessed (Hair, 2016). The study found that the $p$-value of the $X^{2}$ test was significant at 0.000 level. Besides, an examine of a good fit for the structural model was conducted $\left(X^{2}=100.289, \mathrm{df}=51, X^{2} / \mathrm{df}\right.$ $=1.966, \mathrm{CFI}=0.955, \mathrm{GFI}=0.953, \mathrm{AGFI}=0.928, \mathrm{NFI}=0.914, \mathrm{RMSEA}=0.055, \mathrm{RMR}=0.026, \mathrm{PNFI}=0.706, \mathrm{p}-\mathrm{close}=0.290)$, which confirmed that the hypothesized paths in the proposed models were statistically significant. The results provide the validity of the structural model (Figure 3).

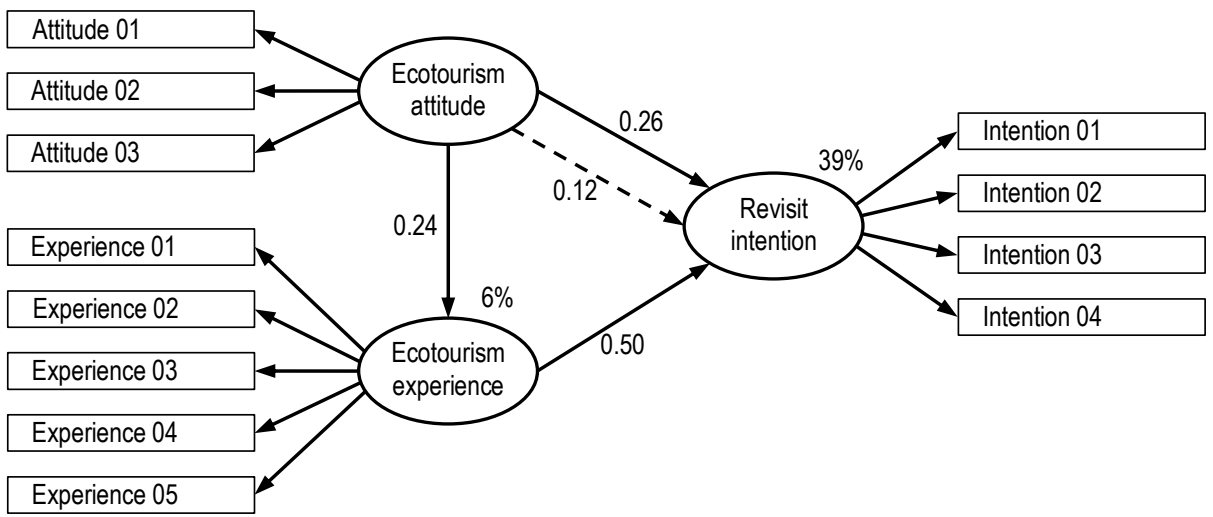

Note: The dashed line refers to the mediating effect of the experience on the relationship between the attitude and the revisit intention. Figure 3: The standardized estimated results of the research model.

(Source: Author)

\subsection{The mediating effect of visit experience on the relationship between attitude and revisit intention, and the total effect} In order to find out the mediating effect of the experience on the relationship between attitude and revisit intention, the study tested the possible relationships of ecotourism attitude and ecotourism experience, ecotourism attitude, and revisit intention, and ecotourism experience and revisit intention. Hair (2016) pointed out that three former simple relationships must be significant, and the effect of ecotourism attitude on revisit intention is reduced when the total relationship of three constructs was once examined.

Analysis revealed that the relationship between three constructs has three direct effects and one indirect effect (Table 4). The direct effect of ecotourism attitude on the ecotourism experience was medium (0.24), whereas that of ecotourism experience on revisit intention was large (0.50). In the path from ecotourism attitude to revisit intention, the study showed a direct effect $(0.26)$ and an indirect effect $(0.12)$ due to the affinity for the mediator of ecotourism experience. Thus the total effect was medium (0.38). The whole model explained $39 \%$ of the variance.

Table 4: Total effect among Ecotourism attitude, ecotourism experience, and revisit intention.

\begin{tabular}{llll}
\hline Path & Direct effect & Indirect effect & Total effect \\
\hline Ecotourism attitude --> Ecotourism experience & $0.24^{* \star}$ & & $0.24^{* \star}$ \\
Ecotourism experience --> Revisit intention & $0.50^{* \star}$ & & $0.50^{* \star *}$ \\
Ecotourism attitude --> Revisit intention & $0.26^{* \star}$ & $0.12^{* \star}$ & $0.38^{* \star *}$ \\
\hline
\end{tabular}

Note: ${ }^{*} p<0.05 ;{ }^{* *} p<0.01 ;{ }^{* * *} p<0.001$

(Source: Author)

\subsection{Summary of the results}

After the analysis, the four proposed hypotheses $(\mathrm{H} 1-\mathrm{H} 4)$ were tested and specified the positive relationship between tourists' attitude, experience, and revisit intention toward ecotourism sites. These findings are consistent with previous researches in the tourism field (Zhang \& Lei, 2012). The structural model indicated that the attitude positively affects the experience and revisit intention. Besides, as same as other previous researches, the ecotourism experience partially mediated the path from ecotourism attitude to revisit intention (Huang \& Liu, 2017), in which the direct impact of the attitude on the revisit intention was 0.26 , and the indirect impact mediated by ecotourism experience was 0.12 (Chien, 2016). Even such indirect effect size was small, but it proved a critical component of the experience in the structural model. Therefore, visitor's experience could be considered an essential phase in the mechanism of tourism management, which can support the tourists' satisfaction, and intention to revisit (Castellanos-Verdugo et al., 2016). 


\subsection{Limitations}

Because of the characteristic conditions of the Sicao community, and Wangcheng west community located in South West of Taiwan, the results of this study might not be the same as studies conducted in different places and different types of tourism. Besides, the data collection was cross-section, so that the study had some limitations refer to time and place, sample sampling methods, and respondents.

\subsection{Conclusion \& Recommendations}

The analysis specified the positive relationship between the attitude, experience, and revisit intention toward ecotourism sites. In this relationship, revisit intention was predicted by the attitude toward ecotourism and the visitor experience. The visitor experience's impact was massive (0.50), whereas the attitude's impact was medium (0.38). However, the study explored that the relationship between the attitude and intention exists a direct effect $(0.26)$ and an indirect effect $(0.12)$ because of the partial mediating impact of the visitor experience. Therefore, visitors' experience was considered a vital role, which could promote tourists' intention to come back to the ecotourism places where they visited. In addition, the visit experience was influenced by the ecotourism attitude with a medium effect size of 0.24 . These findings of the study could provide useful contributions for ecotourism management field. One hand, the ecotourism knowledge should be paid to attention in order to improve the ecotourism attitude. In other hand, the ecotourism managers also need to enrich the tourism types, so that the need of ecotourism experience is satisfied. Based on these elements, the ecotourism could make the attractive and consolidate the tourists' intention to revisit.

\section{Acknowledgements}

This research was funded by a grant from the Ministry of Science and Technology Taiwan with the project number: MOST 102-2511S-006-001.

\section{Paper contribution to the related field of study}

Through the findings of this research, the paper pointed out that ecotourism could be sustainably developed if the revisit intention of tourists is further focused. Besides the conservation and preservation of the natural environment and traditional characteristic culture, the managers in the tourism field also could think further how to open different services, so that the travelers have more chances, as well as have more ways to approach the ecotourism. When the attitude and the experience of tourists toward ecotourism are satisfied, it will be not only the useful factor that attracts the revisit of tourists, but also will be the interesting tourism experience that the tourists want to share with family and friends.

\section{References}

Ajzen, I. (2001). Nature and operation of attitudes. Annual review of psychology, 52(1), 27-58.

Ashok, S., Tewari, H., Behera, M., \& Majumdar, A. (2017). Development of ecotourism sustainability assessment framework employing Delphi, C\&I and participatory methods: A case study of KBR, West Sikkim, India. Tourism Management Perspectives, 21, 24-41.

Aswita, D. (2018). Environmental education and ecotourism for sustainable life: Literature study. Jurnal Ilmiah Peuradeun, 6(1), 17-30.

Bazazo, I., Nasseef, M. A., Al-Zawaideh, A., Al-Zawaideh, A., \& Al-Dhomaidat, M. (2017). The Impact of the Attitudes towards Ecotourism Benefits on Destination Loyalty. Journal of Management and Strategy, 8(3), 67-79.

Bufquin, D., DiPietro, R., Park, J.-Y., \& Partlow, C. (2017). Effects of social perceptions and organizational commitment on restaurant performance. Journal of Hospitality Marketing \& Management, 26(7), 752-769.

Castellanos-Verdugo, M., Vega-Vázquez, M., Oviedo-García, M. Á., \& Orgaz-Agüera, F. (2016). The relevance of psychological factors in the ecotourist experience satisfaction through ecotourist site perceived value. Journal of Cleaner Production, 124, 226-235.

Chien, M. (2016). An empirical study on the effect of attractiveness of ecotourism destination on experiential value and revisit intention. Applied Ecology and Environmental Research, 15(2), 43-53.

Hair, F. (2016). Joseph et al.(2014). Multivariate data analysis. In: Pearson new International edition. Boston: McGraw-Hill.

Han, H., Hsu, L.-T. J., \& Sheu, C. (2010). Application of the theory of planned behavior to green hotel choice: Testing the effect of environmental friendly activities. Tourism Management, 31(3), 325-334.

Huang, Y.-C., \& Liu, C.-H. S. (2017). Moderating and mediating roles of environmental concern and ecotourism experience for revisit intention. International Journal of Contemporary Hospitality Management.

Hultman, M., Kazeminia, A., \& Ghasemi, V. (2015). Intention to visit and willingness to pay premium for ecotourism: The impact of attitude, materialism, and motivation. Journal of Business Research, 68(9), 1854-1861.

Lee, T. H., \& Jan, F.-H. (2018). Ecotourism behavior of nature-based tourists: An integrative framework. Journal of Travel Research, 57(6), 792-810. 
Lee, W. H., \& Moscardo, G. (2005). Understanding the impact of ecotourism resort experiences on tourists' environmental attitudes and behavioural intentions. Journal of sustainable tourism, 13(6), 546-565.

Liu, C.-H., \& Huang, Y.-C. (2017). A natural capital model of influences for ecotourism intentions and the buffering effects of emotional values. Journal of Travel \& Tourism Marketing, 34(7), 919-934.

Oviedo-García, M. Á., Castellanos-Verdugo, M., Vega-Vázquez, M., \& Orgaz-Agüera, F. (2017). The Mediating roles of the overall perceived value of the ecotourism site and attitudes towards ecotourism in sustainability through the key relationship ecotourism knowledge-ecotourist Satisfaction. International Journal of Tourism Research, 19(2), 203-213

Reimer, J. K., \& Walter, P. (2013). How do you know it when you see it? Community-based ecotourism in the Cardamom Mountains of southwestern Cambodia. Tourism Management, 34, 122-132.

Zhang, H., \& Lei, S. L. (2012). A structural model of residents' intention to participate in ecotourism: The case of a wetland community. Tourism Management, 33(4), 916925 .

Zhang, H., \& Lin, S.-H. (2011). Affective appraisal of residents and visual elements in the neighborhood: A case study in an established suburban community. Landscape and Urban Planning, 101(1), 11-21.

Zhang, H., Nam, N. D., \& Hu, Y.-C. (2020). The Impacts of Visual Factors on Resident's Perception, Emotion and Place Attachment. Environment-Behaviour Proceedings Journal, 5(14), 237-243 